\title{
Cardiac myxoma: Echocardiography may not suffice!
}

\author{
Nikhil Prakash Patil, MS, MRCS (England), ${ }^{a}$ Karuna Katti, MS, ${ }^{\mathrm{b}}$ and Deepak Kumar Satsangi, $\mathrm{MCh}^{\mathrm{a}}$
}

A 42-year-old man was referred to us for a single left atrial myxoma diagnosed on transthoracic echocardiography. Surgical excision of the myxoma was planned. An intraoperative transesophageal echocardiogram detected an additional mass in the right atrium, along with free mobility and prolapse of the myxoma from the left atrium to the left ventricle (Figure 1). However, after atriotomy, a total of 4 myxomas were excised, 2 from either side of the interatrial septum (Figure 2, $A$ to $C$ ). Hematoxylin-eosin staining of the excised masses demonstrated spindle-shaped cells in a loose myxoid stroma (Figure 2, D), consistent with the diagnosis of myxoma. The initial diagnosis of a single,

From the Department of CTVS, ${ }^{\text {a }}$ G.B. Pant Hospital, New Delhi; and the Department of Anatomy, ${ }^{\mathrm{b}}$ SGT Medical College, Gurgaon, India.

Disclosures: Authors have nothing to disclose with regard to commercial support.

Received for publication Feb 12, 2011; accepted for publication Feb 22, 2011; available ahead of print April 1, 2011.

Address for reprints: Nikhil Prakash Patil, MS, MRCS (England), Department of CTVS,

GB Pant Hospital, New Delhi 110002, India (E-mail: drnikhilp@gmail.com).

J Thorac Cardiovasc Surg 2011;142:453-4

$0022-5223 / \$ 36.00$

Copyright (C 2011 by The American Association for Thoracic Surgery doi:10.1016/j.jtcvs.2011.02.031 left atrial myxoma was thus revised to a final diagnosis of quadruple, biatrial myxomas. The patient's family history and echocardiographic screening of his relatives were not contributory.

Myxomas are the most common primary cardiac tumors, and as many as 6 coexistent myxomas have been documented in literature. ${ }^{1}$ Although they are histologically benign, the malignant potential of myxomas remains debatable; recurrences and multifocal disease occur frequently in the familial setting. ${ }^{2}$ Although echocardiography remains the primary diagnostic modality, additional myxomas may be missed on echocardiography, as in this case. Hence, surgical vigilance with thorough inspection of cardiac chambers on the operating table is warranted to avoid potential complications such as embolism and atrioventricular obstruction.

\section{References}

1. Jugdutt BI, Rossall RE, Sterns LP. An unusual case of recurrent left atrial myxoma. Can Med Assoc J. 1975;112:1099-100.

2. Shinfeld A, Katsumata T, Westaby S. Recurrent cardiac myxoma: seeding or multifocal disease? Ann Thorac Surg. 1998;66:285-8.
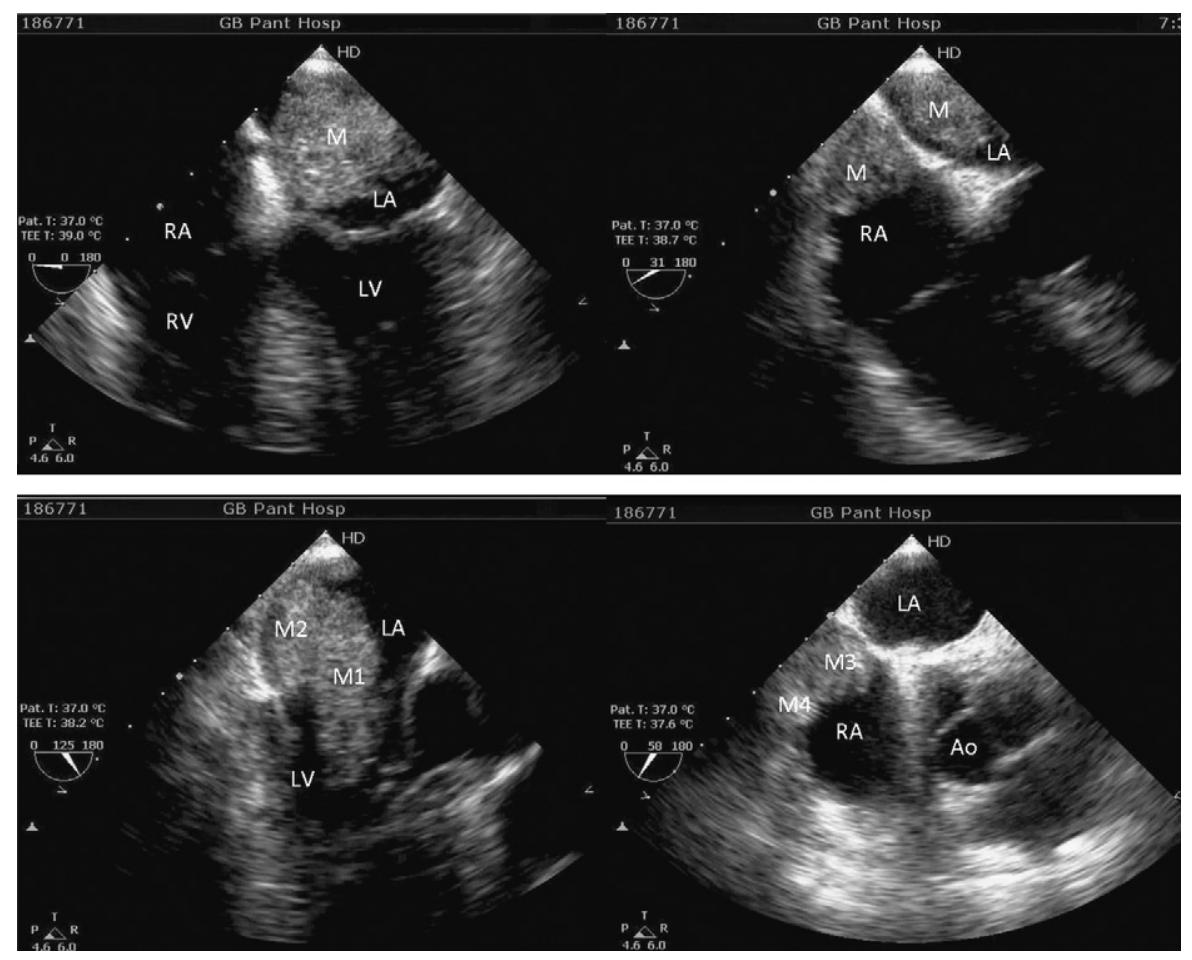

FIGURE 1. An intraoperative transesophageal echocardiogram detected an additional mass in the right atrium, along with free mobility and prolapse of the myxoma from the left atrium to the left ventricle. $M$, Mass; $R A$, right atrium; $L A$, left atrium; $L V$, left ventricle; $R V$, right ventricle; $A o$, aorta. 


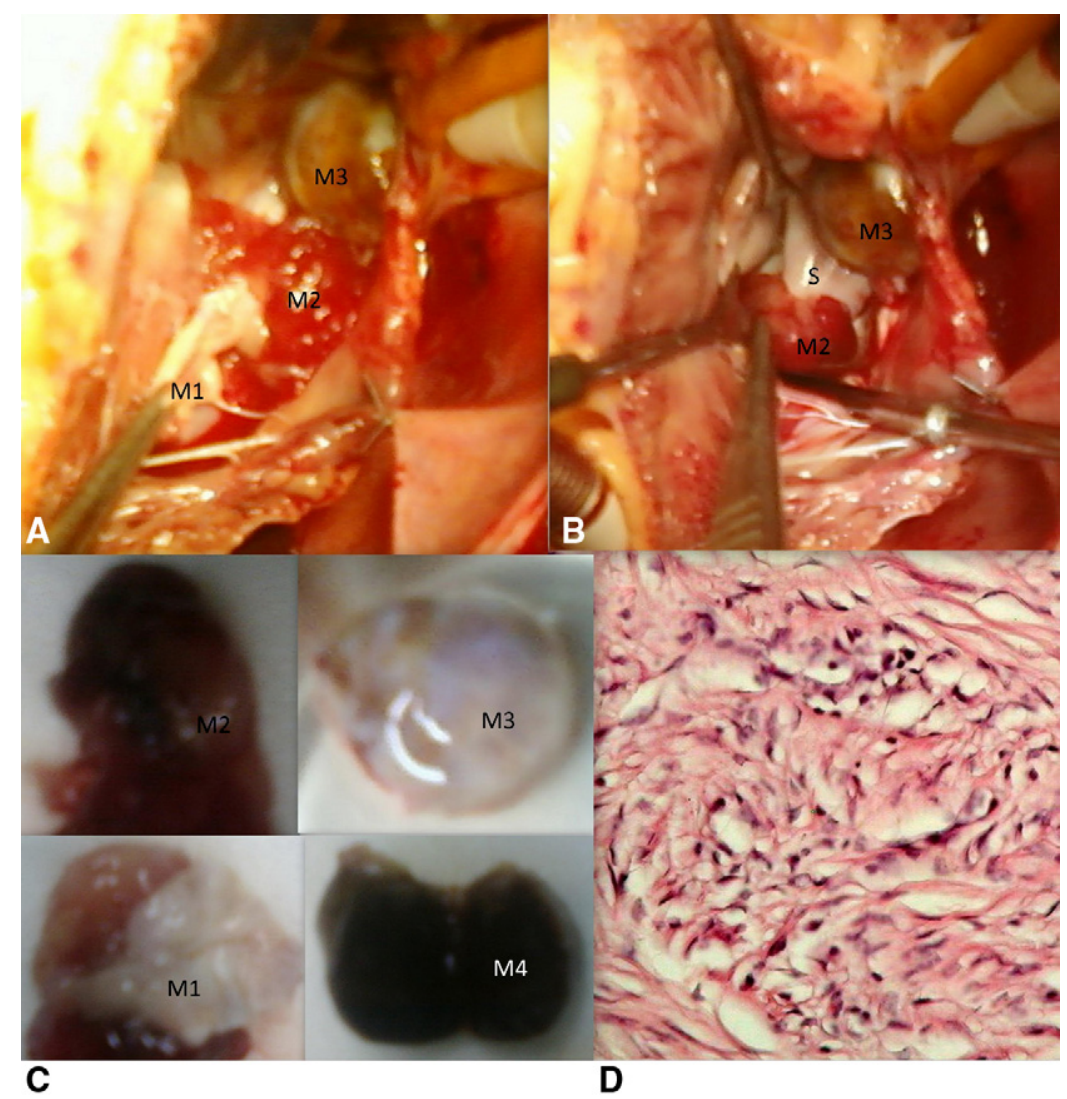

FIGURE 2. A-C, After atriotomy, a total of 4 myxomas ( $M 1-M 4$, numbered sequentially) were excised, 2 from either side of the interatrial septum ( $S$ ). D, Hematoxylin-eosin staining of the excised masses demonstrated spindle-shaped cells in a loose myxoid stroma, consistent with the diagnosis of myxoma. 